\title{
Mortality from infectious pneumonia in metal workers: a comparison with deaths from asthma in occupations exposed to respiratory sensitisers
}

\author{
K T Palmer, ${ }^{1}$ P Cullinan, ${ }^{2}$ S Rice, ${ }^{3}$ T Brown, ${ }^{3}$ D Coggon ${ }^{1}$
}

- Table 4 is published online only at http://thorax.bmj.com/ content/vol64/issue11

${ }^{1}$ MRC Epidemiology Resource Centre, University of Southampton, Southampton, UK; ${ }^{2}$ Department of Occupational and Environmental Medicine, Imperial College, London, UK; ${ }^{3}$ Mathematical Sciences Unit, Health and Safety Laboratory, Buxton, UK

Correspondence to:

Professor K T Palmer, MRC

Epidemiology Resource Centre,

Southampton General Hospital,

Tremona Road, Southampton

S0166YD, UK; ktp@

mrc.soton.ac.uk

Received 23 January 2009

Accepted 15 July 2009

Published Online First

20 August 2009

\begin{abstract}
Background: National analyses of mortality in England and Wales have repeatedly shown excess deaths from pneumonia in welders. During 1979-90 the excess was attributable largely to deaths from lobar pneumonia and pneumonias other than bronchopneumonia, limited to men of working age and apparent in other occupations with exposure to metal fumes. The findings for 1991-2000 were assessed and compared with the mortality pattern from asthma in occupations exposed to known respiratory sensitisers.
\end{abstract}

Methods: The Office of National Statistics supplied data on deaths by underlying cause among men aged 16-74 years in England and Wales during 1991-2000, including age and last held occupation. Data were abstracted on pneumonia for occupations with exposure to metal fumes and on asthma for occupations commonly reported to surveillance schemes as at risk of occupational asthma. The expected numbers of deaths were estimated by applying age-specific proportions of deaths by cause in the population to the total deaths by age in each occupational group. Observed and expected numbers were compared for each cause of death.

Results: Among men of working age in occupations with exposure to metal fumes there was excess mortality from pneumococcal and lobar pneumonia (54 deaths vs 27.3 expected) and from pneumonias other than bronchopneumonia (71 vs 52.4), but no excess from these causes at older ages or from bronchopneumonia at any age. The attributable mortality from metal fume exposure was 45.3 excess deaths compared with an estimated 62.6 deaths from occupational asthma.

Conclusion: Exposure to metal fumes is a material cause of occupational mortality. The hazard deserves far more attention than it presently receives.

Successive analyses of occupational mortality for England and Wales have shown increased death rates from pneumonia in welders in a pattern that extends back more than five decades. During 1949-53, 70 deaths were observed compared with 31 expected. ${ }^{1}$ In 1959-63 there were 101 deaths compared with 54.9 expected $^{2}$ and, in 1970-2, 66 deaths occurred compared with 42.0 expected. $^{3}$ More recently, an analysis covering the periods 1979-80 and 1982-90 confirmed the association and showed that the excess was attributable largely to deaths from pneumonias other than bronchopneumonia (principally lobar pneumonia), was limited to men below the normal retirement age of 65 years ( 55 deaths from lobar pneumonia observed vs 21.6 expected) and was also evident for several other occupations entailing exposure to metal fumes such as moulders and coremakers and furnacemen in foundries. ${ }^{4}$ In a subsequent casecontrol study of men of working age, ${ }^{5}$ communityacquired pneumonia was associated with occupational exposure to metal fumes in the previous 12 months but not in earlier periods, supporting the hypothesis of a hazard that is reversible following cessation of exposure and that affects the incidence of disease (and not just its fatality). Risks were highest for recent exposure to ferrous metal fumes with lobar pneumonia as the outcome, ${ }^{5}$ and emerging hypotheses posit ferrous fume as a cause of oxidative damage to host lung defences or as a growth nutrient in the ironrestricting environment of the lining of the lung. ${ }^{6}$

Despite this growing body of evidence, the hazard of infectious pneumonia in men with occupational exposure to metal fumes seems to be little appreciated and accorded limited priority in research and preventive effort. To confirm its continuing relevance under more recent working conditions, we extended our analysis of occupational mortality for England and Wales to the latest period for which data are now available (1991-2000). Also, to place the risks in context, we compared the estimated excess of deaths from exposure to metal fumes with estimates in relation to asthma for occupations exposed to known respiratory sensitisers. This was chosen as another occupational lung disease which, by comparison with pneumonia related to metal fumes, receives considerable and appropriate preventive attention. Thus, as well as providing a comparison with mortality from metal fume-associated pneumonia, we offer a national estimate of the burden of asthma deaths arising from occupational causes (for which there is little prior information and some inherent problems in estimation).

\section{METHODS}

The UK Office of National Statistics supplied data on deaths by underlying cause among men aged 16-74 years in England and Wales for 1991-2000, including details of age, last occupation held and social class. Occupations were coded according to the Office of Population Censuses and Surveys (OPCS) 1990 Classification of Occupation ${ }^{7}$ and causes of death according to the International Classification for Diseases, 9th Revision. ${ }^{8}$

From the supplied data we estimated expected numbers of deaths by applying age-specific proportions of deaths by cause in the general population to the total number of deaths at each age in each 
Table 1 Occupations at risk of mortality from occupational asthma

\begin{tabular}{|c|c|}
\hline Reference & Occupation/exposure \\
\hline \multicolumn{2}{|c|}{ Occupations commonly reported to European surveillance schemes as at particular risk of occupational asthma } \\
\hline Ameille $(2003)^{9}$ & $\begin{array}{l}\text { Bakers and pastry makers, health workers, spray painters, hairdressers, woodworkers, farmers } \\
\text { and stockbreeders, cleaners, laboratory technicians, welders, textile workers }\end{array}$ \\
\hline Kogevinas $(1999)^{10}$ & $\begin{array}{l}\text { Farmers, other painters, plastics, cleaners, spray painters, agricultural, other non-metal non- } \\
\text { electrical, textiles, glass and ceramics, chemicals, construction and mining, welders, bakers, } \\
\text { metal-making, other food }\end{array}$ \\
\hline McDonald $(2000)^{11}$ & $\begin{array}{l}\text { Laboratory technicians and assistants, nurses, farm and farm hands, woodworkers, food } \\
\text { processors (excluding bakers), bakers, plastic workers, chemical processors, other material } \\
\text { processors (excluding metal and electrical), welders, solderers and electronic assembly workers, } \\
\text { coach and other spray painters }\end{array}$ \\
\hline Karjalainen $(2000)^{12 *}$ & $\begin{array}{l}\text { Veterinary workers, agricultural forestry and fishery workers, farmers, animal husbandry workers, } \\
\text { other farming and animal husbandry work, welders and flame cutters, floor layers, plywood and } \\
\text { fibreboard workers, woodworking machine operatives, other painters and lacquerers, bakers, } \\
\text { butchers and sausage makers, process food preparers, other food and beverage manufacturing } \\
\text { work, other chemical processing workers, plastic product workers, chefs, cooks and cool buffet } \\
\text { managers, hairdressers and beauticians }\end{array}$ \\
\hline \multicolumn{2}{|c|}{ Exposures/occupations linked with deaths from occupational asthma } \\
\hline Fabbri $(1988)^{13}$ Carino $(1997)^{14}$ & Isoscyates \\
\hline Ehlich $(1994)^{15}$ & Baker \\
\hline Liss $(1999)^{16}$ & Wood dust, persuphate \\
\hline Ortega $(2002)^{17}$ (review) & Laboratory work, food processing, baking, milling, autobody painting \\
\hline
\end{tabular}

* Male occupations with an annual incidence rate at least twice that of all occupations combined.

occupational group. Expected numbers were adjusted for social class.

We abstracted data on pneumonia (ICD-9 480-483, 485, 486) for occupations with exposure to metal fume defined a priori ${ }^{4} 6$ (welders, moulders and coremakers, furnace operatives, sheet metal workers and other metal manufacturers) and on asthma (ICD-9 125) for a selection of occupations commonly reported to European surveillance schemes as at special risk of sensitiserinduced occupational asthma (eg, workers in textiles, plastics, health care, agriculture, animal handling, baking, spray painting, woodworking and electrical assembly) ${ }^{9-12}$ and/or in which deaths from occupational asthma have been documented (table 1). ${ }^{13-17}$

In compiling the final choice of occupational codes for asthma, we focused on occupations where we judged exposure to sensitisers to be fairly common and excesses of mortality to be plausibly related to occupation rather than to chance. Two authors (KTP and PC) chose the codes independently, with any differences of opinion being resolved by consensus. Choices were made blind to data on mortality by occupation.

Observed and expected numbers were compared for each cause of death and proportional mortality ratios (PMRs) calculated with 95\% confidence intervals (CI) based on the Poisson distribution. Deaths from pneumonia in occupations involving metal fume exposure were analysed separately for men aged
16-64 years and 65-74 years, as well as overall. To estimate attributable deaths from pneumonia in workers exposed to metal fumes, we calculated the difference between observed and expected numbers of deaths at age 16-64 years, since the increase in risk is known to be short-lived and unlikely to extend beyond retirement. ${ }^{45}$ However, given the known persistence of airways irritability in cases of occupational asthma and the potential for attributable deaths to occur after retirement, we counted excess deaths from asthma at ages 16-74 years.

\section{RESULTS}

Among men of working age (16-64 years) who had worked in occupations with exposure to metal fumes, there were excesses of mortality from pneumococcal and lobar pneumonia (ICD-9 481: 54 deaths vs 27.3 expected) and from other pneumonias (ICD-9 480, 482-3, 486: 71 deaths vs 52.4 expected), especially viral pneumonia (PMR 299) and other bacterial pneumonia (PMR 237) (table 2). However, no excess was found from these causes at older ages or from bronchopneumonia (ICD-9 486) at any age.

Among men of working age, excesses of pneumococcal and lobar pneumonia were noteworthy in welders (PMR 242), in moulders and coremakers (PMR 300) and in sheet metal workers (PMR 268) (table 3).

Table 2 Mortality from pneumonia among men in metal working occupations* in England and Wales, 1991-2000

\begin{tabular}{|c|c|c|c|c|c|c|}
\hline \multirow[b]{2}{*}{ Type of pneumonia $\dagger$} & \multicolumn{3}{|c|}{ Ages $16-64$ years } & \multicolumn{3}{|c|}{ Ages $65-74$ years } \\
\hline & Observed & Expected & PMR (95\% CI) & Observed & Expected & PMR (95\% CI) \\
\hline $\begin{array}{l}\text { Pneumococcal and unspecified } \\
\text { lobar (481) }\end{array}$ & 54 & 27.3 & 198 (149 to 258 ) & 44 & 40.4 & 109 (79 to 146$)$ \\
\hline \multicolumn{7}{|l|}{ Other and unspecified pneumonia } \\
\hline Viral (480) & 6 & 2.0 & 299 (110 to 650$)$ & 0 & 0.9 & $0(0$ to 400$)$ \\
\hline Other bacterial (482) & 10 & 4.2 & 237 (114 to 436$)$ & 2 & 3.7 & 54 (6 to 194) \\
\hline Organism unspecified (486) & 53 & 44.4 & $119(89$ to 156$)$ & 106 & 101.9 & 104 (85 to 126$)$ \\
\hline Other specified pneumonia (483) & 2 & 1.8 & 108 (13 to 392$)$ & 0 & 1.1 & $0(0$ to 322$)$ \\
\hline Bronchopneumonia (485) & 117 & 123.9 & 94 (78 to 113$)$ & 400 & 415.3 & 96 (87 to 106 ) \\
\hline
\end{tabular}

PMR, proportional mortality ratio.

*0ccupations as defined in table 3. †International Classification for Diseases, 9th revision codes given in parentheses. 
Table 3 Mortality from pneumonia among men aged 16-64 years in metal working occupations in England and Wales, 1991-2000

\begin{tabular}{|c|c|c|c|c|c|c|c|c|c|}
\hline Occupations* & \multicolumn{3}{|c|}{$\begin{array}{l}\text { Pneumococcal and unspecified lobar } \\
\text { pneumonia (ICD-9 481) } \dagger\end{array}$} & \multicolumn{3}{|c|}{ Bronchopneumonia (ICD-9 485) } & \multicolumn{3}{|c|}{$\begin{array}{l}\text { Other and unspecified pneumonia (ICD-9 } 480 \\
482,483,486) \dagger\end{array}$} \\
\hline Welders (149) & 32 & 13.2 & 242 (166 to 342$)$ & 54 & 59.4 & 91 (68 to 119$)$ & 45 & 25.9 & 174 (127 to 233$)$ \\
\hline $\begin{array}{l}\text { Moulders and coremakers } \\
\text { (metal) (116) }\end{array}$ & 5 & 1.7 & $300(97$ to 701$)$ & 7 & 8.3 & 84 (34 to 173$)$ & 2 & 3.4 & 59 (7 to 213$)$ \\
\hline Other metal manufacturers (120) & 3 & 6.5 & $46(10$ to 135$)$ & 21 & 27.8 & 76 (47 to 115 ) & 12 & 11.2 & 107 (56 to 188$)$ \\
\hline
\end{tabular}

PMR, proportional mortality ratio.

${ }^{*}$ As defined in OPCS classification of occupation (OPCS codes given in parentheses). †International Classification for Diseases, 9th revision code.

Assuming the excess of attributable deaths was confined to men of working age dying of pneumococcal and lobar pneumonia and pneumonias other than bronchopneumonia, table 2 suggests an attributable mortality from occupational metal fume (excess of observed vs expected) of 45.3 deaths. This compared with an estimated 62.6 excess of observed vs expected deaths from asthma over the same time interval among men aged 16-74 years from the occupations listed in table 4 in the online supplement (overall PMR 110, 95\% CI 102 to 118), among whom synthetic fibre makers (PMR 740), other textile processing operatives (PMR 254), dental technicians (PMR 230) and other health professionals (PMR 223) showed the most noteworthy relative increases in mortality.

\section{DISCUSSION}

In keeping with national analyses of occupational mortality covering earlier periods, we found an excess of deaths from pneumonia among male welders during 1991-2000. Following the model of one previous analysis, ${ }^{4}$ we also confirmed that the excess risk extended to other workers with occupational exposure to metal fumes, was principally confined to deaths from lobar pneumonia and was limited to men below the normal retirement age of 65 years. As in an earlier report, the absence of an association with bronchopneumonia provided evidence against confounding by smoking. Assuming a shortterm reversible effect of work, the estimated excess of deaths among 16-64-year-olds was about 45 over the decade in question, and was material in comparison with (although lower than) the 63 deaths we ascribed to occupational asthma.

This analysis and interpretation has several limitations. Death certification over the study period is likely to have been almost complete, but with the potential for misclassification of cause of death. For example, some deaths from occupational asthma in bakers could have been ascribed to chronic obstructive pulmonary disease, a recognised problem in recording asthma deaths in general. ${ }^{18}$ This would lead to an underestimate of mortality from asthma in the occupations selected for study, but in both the observed and expected counts, so would not necessarily bias an estimate of risk difference. On the other hand, part of the excess asthma mortality in the occupations in table 4 may have arisen by chance rather than as a consequence of occupational sensitisation (the risk ranking of occupations by mortality did not correspond exactly to what might be expected from statistics on morbidity ${ }^{11}$ ); we did not have access to detailed clinical data or post-mortem findings on individuals. Deaths from chemical pneumonitis might have been ascribed to unspecified pneumonia, but large-scale misdiagnosis as pneumococcal or lobar pneumonia (the main outcome) seems unlikely, and there is empirical evidence against it from earlier investigations. ${ }^{4}$
Misclassification of exposure is another possibility. Death certificates in the UK record the last held occupation which, for some subjects, may have preceded death by several years. Cases of occupational asthma may have arisen during earlier employments that were changed because of chronic symptoms or health advice (unhealthy worker selection bias). Under-attribution of deaths from occupational asthma could thus arise in the occupations chosen for analysis. This is less likely in relation to deaths from pneumonia as fatal cases of the illness will typically have had a rapid onset, with less opportunity to occasion a change of employment.

Other ways in which exposure misclassification can arise include heterogeneity of exposure experience in workers who share a common job title and the selection of occupations for inclusion in our analysis. All welders are likely to have been exposed to metal fumes within their job and all bakers to flour dust, but only a proportion of textile process workers will have been exposed to reactive dyes and, similarly, only a minority of coach painters and vehicle body repairers to isocyanates.

Other factors being equal, the inclusion of an occupation in which a minority of workers have relevant exposure will not bias estimates of risk difference (observed minus expected numbers), but the larger the pool of occupations selected, the greater the potential for plays of chance or unrecognised confounding to conceal genuine differences measured on an absolute scale. The risk of including too many occupations in an analysis, however, has to be weighed against the potential to include too few and thereby omit occupations in which cases may arise. Table 4, although based on an appraisal of current awareness, may not have included every occupation in which an attributable case of fatal asthma arose. In fact, as Leigh et al point out, "no data are available that unambiguously count the number of deaths nationally from occupational asthma", ${ }^{19}$ and the methodology for doing so is not yet well established. Thus, for example, a Swedish registry survey which highlighted differences in asthma mortality by occupation could not estimate the occupation attributable mortality in the absence of a rule for counting attributable deaths. ${ }^{20}$

The estimates for asthma in this paper are therefore tentative and do not include the additional toll arising from workaggravated asthma. However, they serve to illustrate that the mortality risk of occupational exposure to metal fumes is not inconsiderable relative to another well-recognised respiratory hazard of public health significance and concern.

Occupational and work-aggravated asthma have other welladvertised and important consequences in terms of chronic ill health and hospitalisation episodes. To a degree, infectious pneumonia induced by exposure to metal fumes is also a source of morbidity. Only a minority of cases are fatal, but the increased risk extends to non-fatal cases admitted to hospital with serious illnesses. ${ }^{5}$ 
We conclude that the hazard of occupational exposure to metal fumes is an ongoing problem, still detectable after more than five decades, and the hazard deserves far more priority than it presently receives.

Acknowledgements: We are grateful to the Office of National Statistics for supplying the data on which these analyses are based. Clare Harris assisted with data cleaning, sorting and checking. Sue Curtis helped prepare the manuscript.

Competing interests: None.

Provenance and peer review: Not commissioned; externally peer reviewed.

\section{REFERENCES}

1. Registrar General. Decennial Supplement England and Wales 1951. Occupational mortality: Part II, Vol 1. London: HMSO, 1958.

2. Registrar General. Decennial Supplement England and Wales 1961. Occupational mortality tables. London: HMSO, 1971.

3. Registrar General. Decennial Supplement England and Wales 1971. Series DS no 1. London: HMSO, 1981.

4. Coggon D, Inskip H, Winter $\mathrm{P}$, et al. Lobar pneumonia: an occupational disease in welders. Lancet 1994;344:41-4.

5. Palmer KT, Poole J, Ayres JG, et al. Exposure to metal fume and infectious pneumonia. Am J Epidemiol 2003:157:227-33.

6. Palmer K, Coggon D. Does occupational exposure to iron promote infection? Occup Environ Med 1997:54:529-34.
7. Office of Population Censuses and Surveys. Standard occupational classification 1990. London: HMSO, 1990.

8. CDC National Center for Health Statistics. International classification of diseases Ninth revision. http://www.cdc.gov/nchs/about/major/dvs/icd9des.htm.

9. Ameille J, Pauli G, Calastreng-Crinquand A, et al. Reported incidence of occupational asthma in France, 1996-99: the ONAP programme. Occup Environ Med 2003:60:136-41.

10. Kogevinas M, Antó JM, Sunyer J, et al. Occupational asthma in Europe and other industrialised areas: a population-based study. Lancet 1999;353:1750-4.

11. McDonald JC, Keynes HL, Meredith SK. Reported incidence of occupational asthma in the United Kingdom, 1989-97. Occup Environ Med 2000;57:823-9.

12. Karjalainen A, Kurppa K, Virtanen S, et al. Incidence of occupational asthma by occupation and industry in Finland. Am J Ind Med 2000;37:451-8.

13. Fabbri LM, Danieli D, Crescioli S, et al. Fatal asthma in a subject sensitised to toluene diisocyanate. Am Rev Respir Dis 1988:137:1494-8.

14. Carino M, Aliani M, Lieitra C, et al. Death due to asthma at workplace in a diphenylmethane diisocyanate-sensitized subject. Respiration 1997;64:111-3.

15. Ehlich RI. Fatal asthma in a baker: a case report. Am J Ind Med 1994:26:799-802

16. Liss GM, Tarlo SM, Banks D, et al. Preliminary report of mortality among workers compensated for work-related asthma. Am J Ind Med 1999;35:465-71.

17. Ortega HG, Kreiss K, Schill DP, et al. Fatal asthma from powdering shark cartilage and review of fatal occupational asthma literature. Am J Ind Med 2002;42:50-4.

18. Sears MR, Hiller HH, de Boer G, et al. Accuracy of certification of deaths due to asthma: a national study. Am J Epidemiol 1986;124:1004-11.

19. Leigh JP, Romano PS, Schenker MB, et al. Costs of occupational COPD and asthma Chest 2002;121:264-72.

20. Torén K, Hörte LG, Järvholm B. Occupation and smoking adjusted mortality due to asthma among Swedish men. Br J Ind Med 1991:48:323-6. 